\title{
Students' implicit epistemologies when working at the intersection of engineering and the arts
}

\author{
Joshua Cruz ${ }^{1}$, Noa Bruhis², Nadia Kellam² and Suren Jayasuriya ${ }^{2^{*}}$ (D)
}

\begin{abstract}
Background: This paper explores the epistemologies and discourse of undergraduate students at the transdisciplinary intersection of engineering and the arts. Our research questions focus on the kinds of knowledge that students value, use, and identify within an interdisciplinary digital media program, as well as how they talk about using these epistemologies while navigating this transdisciplinary intersection. Six interviews were conducted with students pursuing a semester-long senior capstone project in the digital culture undergraduate degree program in the School of Arts, Media and Engineering at Arizona State University that emphasizes the intersection between arts, media, and engineering.

Results: Using deductive coding followed by discourse analysis, a variety of student epistemologies including positivism, constructionism, and pragmatism were observed. "Border epistemologies" are introduced as a way to think and/or construct knowledge with differing value across disciplines. Further, discourse analysis highlighted students' identifications with being either an artist or an engineer and revealed linguistic choice in how students use knowledge and problem-solve in these situations.
\end{abstract}

Conclusions: Students in a digital media program use fluid, changing epistemological viewpoints when working on their projects, partly driven by orientations with arts and/or engineering. The findings from this study can lead to implications for the design and teaching of transdisciplinary capstones in the future.

Keywords: Epistemology, STEAM, Transdisciplinary, Discourse analysis

\section{Introduction}

Engineering education research, while a relatively new academic discipline, has been situated strategically to tackle grand challenges in the formation of engineers through primary, secondary, and post-secondary education. In particular, these challenges include advancing holistic engineering formation through interdisciplinary work and fostering creative skills (Rogers \& Freuler, 2015; Tranquillo, 2013). However, research literature, while positive on the beneficial effects of interdisciplinarity, has argued that fostering creativity for engineering requires transdisciplinarity (Ertas et al., 2003).

\footnotetext{
* Correspondence: sjayasur@asu.edu

${ }^{2}$ Arizona State University, Tempe, AZ 85281, USA

Full list of author information is available at the end of the article
}

Transdisciplinarity, as opposed to interdisciplinarity or multidisciplinarity, synthesizes tools and knowledge from different domains of expertise so that they are no longer recognizable by any single domain (Lattuca et al., 2004). Such synthesis encourages effective thinking skills, development of multiple perspectives, and the ability to traverse domain boundaries comfortably. While difficult to achieve in practice, transdisciplinary education would help arm the engineer of the future with cognitive skills to tackle complex socio-technical problems of the twenty-first century.

One recent thrust in transdisciplinarity for engineering education is the emphasis on Science, Technology, Engineering, Arts, and Mathematics (STEAM), or STEM + arts. Advocates claim that the arts (and sometimes

\section{Springer Open}

(c) The Author(s). 2021 Open Access This article is licensed under a Creative Commons Attribution 4.0 International License, which permits use, sharing, adaptation, distribution and reproduction in any medium or format, as long as you give appropriate credit to the original author(s) and the source, provide a link to the Creative Commons licence, and indicate if changes were made. The images or other third party material in this article are included in the article's Creative Commons licence, unless indicated otherwise in a credit line to the material. If material is not included in the article's Creative Commons licence and your intended use is not permitted by statutory regulation or exceeds the permitted use, you will need to obtain permission directly from the copyright holder. To view a copy of this licence, visit http://creativecommons.org/licenses/by/4.0/. 
humanities) help foster creativity and divergent thinking models for Science, Technology, Engineering, and Mathematics (STEM) students (Henriksen, 2014; Maeda, 2013; Oner et al., 2016). While various STEAM efforts have fallen into all categories of multi-, inter-, and transdisciplinarity, they have been lauded for broadening participation and diversity (in gender, race, socio-economic class, and viewpoint) for underrepresented groups. The arts/humanities often deal with issues of social and cultural awareness and justice, and thus integrating arts/humanities could bring these issues to the forefront of STEM disciplines.

Yet, the literature does contain some criticisms of STEAM. Artists have critiqued STEAM for making value judgments about art and for applying a positivist position to this judgment, to which STEM fields typically ascribe. The utilitarian use of arts as a way to benefit STEM can feel like instrumental justification (Sochacka et al., 2016). Further, actual interactions with engineers and artists can yield discomfort or tense interactions. In narrative inquiries for an interdisciplinary design studio, researchers described this discomfort for engineering and arts students working together (Guyotte et al., 2015). All of these issues require us to reconsider how to incorporate the arts into STEM education without reducing or diminishing the arts. In this research, we are focusing our efforts on the relationship between engineering (the E in STEM) and the arts.

Our central hypothesis is that tension in engineer's and artist's interactions may be attributed to varying epistemological differences across disciplines. We argue that epistemologies consist of a set of beliefs about knowledge held by individuals that dictate either the epistemic foundational status of truth in the world (e.g., there exists one right answer or there exists multiple right answers) or constitute the process or criteria for which one evaluates or determines knowledge. These differing epistemologies, and the process to acquire them, can potentially cause divergence in value systems across the domains. Further, a key insight of this research paper is the importance of language, namely discourse, which is used to talk about and establish knowledge across disciplines. Discourse can significantly vary from discipline to discipline. Thus, interactions between STEM and the arts may be difficult due to foundational epistemological and linguistic issues, which have not been adequately studied in the intersection of engineering and the arts. To study these issues within a transdisciplinary engineering and arts learning environment, we collected and analyzed qualitative data from students from the School of Arts, Media and Engineering (AME) at Arizona State University.

\section{Research context}

AME was created to train the next generation of media artists and scientists in digital technologies and experiential media systems (Rikakis et al., 2006). AME inherently straddles engineering and the arts, where students use tools and vocabulary from either domain in their work. The undergraduate degree is a B.A. or B.S. in Digital Culture (DC), and sample classes in the department include "media editing" which focuses on digital processing skills with audio and visual/graphical content, "digital physical systems" which combines embedded electronics such as Arduinos and microcontrollers with technologies such as 3D printing, and "animating virtual worlds" which focuses on virtual and mixed/augmented reality. Some undergraduates go into STEM careers such as graphic design, software engineering, 3D modeling, and audio/visual media.

The course sequence, AME 485/486 Digital Culture Capstone I/II, is a requirement for undergraduate students in AME. Projects contain multidisciplinary material from both arts/humanities and science/engineering. The course typically enrolls 40-60 students, with students working in groups of three to five on projects. Students develop the idea for their projects, pursue these projects over one semester, and present the results of the work in a public showcase and a formal write-up. Groups typically have an assigned faculty mentor to guide them on this process.

More specifically, the course of the capstone typically involves students self-assembling into groups after performing 2 weeks of teaming exercises and brainstorming activities facilitated by instructors. Then, student groups give a 5-min project proposal/pitch to faculty and other students, who give critical feedback on their idea. This is the point when faculty mentors are assigned. Students work on their ideas, iterating both the engineering development of their prototypes (either in physical or digital formats) and the narrative and themes of the project. One month before the end of the semester, students have a mock presentation day as a dry-run and receive feedback. On the final day, the work is presented in a showcase open to the public, and a final report with references and appropriate research is required as the final deliverable for the capstone.

\section{Research questions}

By understanding the epistemologies and discourse/linguistic choice present at the boundary of engineering and the arts, we hope to analyze engineering-art student interactions. In particular, our research questions for this study are the following:

RQ1: What implicit epistemologies can be discerned when students describe their approach to coursework that is a blending of arts and engineering?

RQ2: In the absence of specific vocabulary to indicate epistemological orientations, what language do students use that reflects their epistemological orientations? 
RQ3: How do students' personal beliefs and epistemological alignments inform the way that they navigate their AME coursework?

For the rest of the paper, we approach these research questions using techniques from qualitative research to provide rich and thick descriptions of these transdisciplinary boundaries. First, we situate ourselves within the literature on educational and engineering epistemology and follow by elaborating on our own theoretical framework of epistemology, which guided our data analysis. We then describe our qualitative approach and data collection. Finally, we present our findings to answer these three research questions as well as a discussion about the broader implications of our findings for the engineering education research community and various stakeholders.

\section{Background}

\section{Epistemology in engineering education}

Epistemology has been studied actively in education literature, including a sub-branch focusing on engineers. In general education, some of the earliest work was conducted by Perry Jr. (1999) to track personal epistemologies of students. He noted that Harvard male students transitioned from a dualist viewpoint of the existence of singular, absolute truths (knowledge is either right or wrong), through the relativity of competing truths, and finally committed to a prioritized truth based on evidence or reasoning (Perry Jr., 1999). Cunningham and Fitzgerald (1996) traced historical epistemological traditions to modern beliefs commonly present in individuals today and identified three main ways in which a statement or belief is evaluated as "true" or justified: correspondence to reality, internal logical coherence of ideas, and pragmatic utility. Schommer (1990) suggested that there are five dimensions to the concept of student epistemology, including beliefs about the ways that knowledge is structured, the certainty or uncertainty of knowledge, the sources of knowledge, the speed at which one might learn, and one's innate or developed ability to learn. While studies have adopted her model (Carberry et al., 2010; Elby et al., 2016), other studies have taken issue with the way that Schommer has constructed epistemology, attempting to offer other definitions (Hofer, 2001; Hofer \& Pintrich, 1997). An alternative is a theory of personal epistemology, which "retains the explicit multidimensionality of epistemological beliefs [like Schommer's] but implies more integration among an individual's perspectives" (Hofer, 2001, p. 361). Yet, another similar notion is that of epistemological identity (Demerath, 2012). By epistemological identity, we mean those ways of thinking about knowledge (its value, its construction) to which individuals' default. An epistemological identity is an epistemology that resonates most with each individual, so much so that one's identity is enmeshed within their understanding of what counts as knowledge in the world. Throughout this piece, we see Hofer's and Demerath's ideas as overlapping. When we refer to either personal epistemology or epistemological identity, we refer simply to those epistemological orientations from which students are most comfortable operating.

Researchers have recently begun exploring epistemology specifically for engineering and have developed epistemological questions about engineering knowledge (Figueiredo, 2008). Other researchers in science, physics, and educational psychology have advocated domainspecific epistemologies (Greene et al., 2010). We do note that there is a general debate in the literature of whether epistemology should be domain-specific or domaingeneral (Buehl et al., 2002), which is an interesting debate but not one which we take up in this paper. Researchers observed engineering students tend to stick harder to true/not true dualities (Paulsen \& Wells, 1998), though they transition in the last 2 years (Marra et al., 2000). Faber and Benson (2017) noted that engineering students' epistemic beliefs also yield varied results in problem-solving approaches. Montfort et al. (2014) also explored the personal epistemologies of civil engineering faculty and showed that their epistemologies do not necessarily match students' epistemologies. However, we note that there is a large gap in the literature regarding epistemologies in transdisciplinary environments such as the intersection of engineering and the arts, which this study aims to fill.

\section{A need for epistemological diversity in STEM}

There has been a spike in research on STEM student epistemologies over the past 20 years, with a number of Likert-type measurements developed to determine how students in STEM disciplines think, appearing in the late 1990s and 2000s (e.g., Elby, 2001; Halloun \& Hestenes, 1996, 1998; Redish et al., 1998). Many of these instruments have been used in recent studies (e.g., Chen et al., 2019; Sharma et al., 2013; Willoughby \& Johnson, 2017). One drawback of such surveys is that they are developed with an underlying assumption about what constitutes correct or incorrect epistemologies in STEM. Elby (2001), for instance, rates student answers on a scale of sophistication; those who answer in a certain way have a more "sophisticated" understanding of the sciences. While Elby allows for the fact that knowledge is always tentative, there is still an implication that certain ways of constructing knowledge are "better." Two other studies (Halloun \& Hestenes, 1998; Redish et al., 1998) use terminology to designate novice versus expert understandings of physics. As such, these instruments do not 
provide a description of student epistemology per se; rather, they assess student alignments with already established, dominant ways of thinking in the sciences. Dreyfus et al. (2019) note that a similar phenomenon has occurred in the field of physics, but they argue that there are no single domains of knowledge that determine a sophisticated/naive dichotomy within the field.

Additionally, attempts to integrate more diverse epistemological orientations into STEM have been met with resistance. Chesky and Wolfmeyer (2015, p. 31) observe that "the science education research community maintains a commitment to rational thinking and the elitism of scientific knowledge." To think otherwise, in some scientific circles, amounts to extreme relativism. Epistemological constructionism is largely rejected by some in the STEM communities for that reason. In a stance against any kind of relativism in the sciences, Rowlands and Carson (2001, p. 3) argue that "If truth is whatever the learner considers to be the case, then there is no body of knowledge, no 'subject matter' that can be taught as such." If Rowlands and Carson represent a dominant belief within STEM, it would begin to explain the number of epistemological measures for students that center on correct/incorrect ways of thinking. Strong resistance to relativism may be due to a misunderstanding of attributing this relativism to a solipsistic relativism, while the authors of the original articles may be simply expressing the viewpoint that scientific reasoning is confined to the general model and instruments it deploys in use known as scientific perspectivism (Giere, 2010).

In the last decade, there have been various calls for epistemological and ontological diversity in the physical sciences (Douglas, 2016; Figueiredo, 2008; Osbeck \& Neressian, 2017; Yasar \& Veronesi, 2015). These works have shown how such diversity allows students to more freely engage with the source material and enable alternative styles of learning than the traditional ones in the classroom for better understanding. However, little research exists at the intersection of STEM and arts/humanities, where such epistemological diversity may be the most pronounced. One example exists in Dolberry (2015) who argues for more relativist ways of thinking in the sciences. Dolberry, exploring the intersection of hiphop culture, culturally responsive teaching, and STEAM pedagogy, calls for teachers to have an epistemological openness to difference. He specifically argues that those who identify with the hip-hop culture know the world through strong expression, performance, and resistance. As such, "hip-hop STEAM pedagogy places particular importance on the ' $\mathrm{A}$ ' in the acronym, ensuring that esthetics and artistry are a part of scientific learning." Another example exists in Psycharis (2018), who attempted to develop a framework for computational STEAM pedagogy. In this development, he considers what a STEAM epistemology might consist of. While Psycharis admits that the answer is ambiguous, it is clear that a STEAM epistemology must be rooted in transdisciplinarity, complexity, and responsiveness to social needs, both pragmatic and creative. Henriksen et al. (2019) seem to be in agreement with Psycharis, noting that STEAM thinking "blurs the lines of disciplines and is creative and problem- or project-oriented, with realworld complexity" (p. 58). Drawing on Schön (1983), Henrikson et al. suggest that all aspects of STEAM are underlain by principles of design. They further argue that design, as a way of thinking and interacting with the world, may itself be an epistemology. As such, it seems that a STEAM epistemology may be fluid, capable of drawing from various epistemological camps when certain kinds of knowledge are required.

Our project is neither to develop a specific STEAM epistemology as Psycharis (2018) begins to, nor is it to suggest that STEAM has underlying principles that unite different disciplines epistemologically, as Henriksen et al. (2019) or Schön (1983) do. Rather, we attempt to better understand the degree to which students at the border of engineering and arts disciplines draw from different and potentially disparate epistemologies to solve the problems presented within their program. We do not suggest that the dominant epistemological beliefs within STEM disciplines are incorrect, or that there is no value in adhering to a strict paradigmatic approach for problem solving (including rationalism/positivism/pragmatism). Rather, as with Greene (2012), we recognize that there are a variety of ways to question and address social phenomena, all informed by differing epistemologies: "a respectful conversation among these different value sets could perhaps powerfully engender deeper and broader understanding" of the world around us (p. 761). We adopt this attitude as we attempt to understand the experiences of students with potentially diverse epistemological identities in a STEAM-based program.

\section{Theoretical framework}

Our central theoretical foundation lies in epistemology or the philosophical branch of inquiry into the nature of knowledge and how humans come to acquire it. Epistemology is made up from the Greek words episteme (knowledge) and logos (multiple definitions including reasoned discourse, study of [a particular field]). In our work, we refer to epistemologies consisting of a set of beliefs about knowledge held by individuals which dictate either the epistemic foundational status of truth in the world (e.g., there exists one right answer or there exists multiple right answers) or the process or criteria in which one evaluates or determines knowledge. This is similar to the work of Yu and Strobel $(2011,2012)$, who 
attempted to categorize students ontologically as realists (our observations are of a real, verifiable world independent of human interpretation), idealists (the world is constructed out of social discourses), or pragmatists (the value of knowledge rests within its usefulness within the contexts of real-world application). We note that separating epistemological claims from ontological claims about the world is philosophically complicated and "messy." In this paper, we are primarily concerned with students' epistemological beliefs, although we do acknowledge that some students' beliefs about the ontology of the world can leak into these statements (e.g., belief in a real world independent of observation is both epistemic as well as ontological).

To identify these various epistemologies, we adopt a taxonomy of different schools of thought into a set of a priori labels. These schools of thought are taken from the works of Sosa et al. (2008), Staller (2013), and Steup (1996):

- Positivism: belief that there is objective truth, and it is discoverable through the scientific method and rigorous experimentation.

- Post-positivism: relaxation of positivism to allow for subjectivity through the relationship between researcher and research, use of human conjectures, and the ability to potentially have multiple truths.

- Constructionism: knowledge is constructed, contingent upon social processes, other humans, and cultural context.

- Skepticism: no beliefs can truly be justified because of an infinite chain of reasoning, and thus, we have no absolute knowledge of the world.

- Empiricism: emphasizes that experience or sensory/ perceptual data is the primary evidence for supporting beliefs/ideas and ascertaining truth status.

- Rationalism: knowledge is derived from a priori (before experience) concepts and advocates the use of rational argument and logic to ascertain truth status.

- Pragmatism: knowledge is true in so far as it is useful or has explanatory/predictive power.

- Representationalism: there is a separation between the world we see in our consciousness (virtual) and the real world which exists outside this space.

- Post-structuralism: a more extreme version of constructionism, wherein social processes and cultural contexts are constantly shifting. Thus, knowledge is unstable and unattainable both intrinsically (within the person) and extrinsically (across groups).

We use these epistemological camps as ways of teasing out different epistemological identities (Demerath, 2012) that students hold.
It should be noted that this was our initial set of a priori codes based on what was most prominent in the literature. Some of these codes were not used during analysis because we did not find instances of them. We further acknowledge that epistemology is a "messy" term, and there are various other nuanced epistemological positions such as critical realism (Bhaskar, 1997), phenomenology, or practical epistemology (Psycharis, 2018). However, those epistemologies that we choose to highlight are deeply entrenched in methodological literature (Staller, 2013), representing what Tennis (2008) identifies as "some of the most common epistemic stances" (p. 104). As such, we believe they offer a useful heuristic for this particular study without overcomplicating our theoretical framework. Given epistemological messiness, however, we also note that our method (described later) allows for the opportunity to change or make new labels for epistemologies we discover that do not fit comfortably into any of the existing epistemological camps.

An additional difficulty using this framework is that terms like empiricism, pragmatism, and representationalism are not familiar to most students, and thus interviewing students to inquire about their epistemologies must be done in an indirect fashion, requiring the researcher to perform a posteriori identification of their epistemology from interpreting the data. We noticed this effect in a pilot study where more abstract questions about the nature of knowledge did not elicit satisfactory responses from participants due to confusion and vagueness. Our research methods aim to combat this issue by using a qualitative design to elicit and identify epistemologies in student responses, what we are terming their "implicit epistemologies" rather than those that they might explicitly describe if they were more familiar with such theories.

\section{Reflexivity statements of the researchers}

We acknowledge that investigating questions of epistemology involves researchers interpreting data collected from student participants. As such, it is useful to provide a reflexivity statement about the researchers of what underlying assumptions and lenses we use to view the research. The researchers on the team come from different education research backgrounds. Dr. Joshua Cruz has a strong humanities and philosophy background and works in the field of education teaching doctoral-level qualitative method courses. Noa Bruhis is a PhD student in an interdisciplinary major with a background in engineering and expertise as an artist. Dr. Nadia Kellam is an engineering faculty member with expertise in qualitative engineering education research. Finally, Dr. Suren Jayasuriya is a faculty member in the AME program and has a vested interest in philosophy as well as the 
integration of arts and humanities into traditional STEM topics. All the researchers had varying epistemological stances ranging from pragmatism to constructivism, and it was noted that these differing perspectives could potentially be in conflict during the data interpretation phase. To deal with this, the researchers were careful not to prescribe normative statements about epistemologies that arise in students in the study, but rather document and showcase the variety and complexity of knowledge making present. Having one researcher from the AME program allowed for decoding of certain discourses or technical knowledge particular to the media arts and sciences that could be explained to the other researchers. However, like all qualitative research, the backgrounds of each researcher necessarily inform their own work, and we all worked together to navigate conflicts and resolve issues in the interpretation of the data. This involved seeking input from all researchers, identifying where our interpretations differed, and either coming to an agreement or in some cases noting alternative viewpoints in the text where appropriate.

\section{Methods}

Our qualitative design consisted of semi-structured interviews analyzed with a priori coding followed by discourse analysis; it is not uncommon for qualitative methods to use two forms of analysis (Morse, 2010; Morse \& Niehaus, 2009). Advantages of this two-step design include further triangulation of the findings within the data, richer descriptions of the data from multiple viewpoints, and improved transferability of the method to other studies (Firestone, 1993; Shenton, 2004).

There are several methodological choices we made to arrive at our final qualitative research design. Quantitative methods, including the use of surveys to ascertain student epistemologies, did not satisfy the thick descriptions of these epistemologies we wanted to learn about. Thus, we decided to use qualitative research techniques, designed to reflect richer and in-depth experiences of our participants (Creswell \& Creswell, 2018). To analyze participant's language, we employed the use of discourse analysis as the study of language-in-use (Gee, 2014) at a micro-scale. However, discourse analysis can be timeconsuming and is not easily scalable to $6+$ hour-length interviews, so we first used a priori coding to identify key passages in interviews of epistemologically rich content. We then performed discourse analysis on these passages to elucidate student's language and thoughts on knowledge and problem-solving. Finally, we returned to a higher level by replacing our existing a priori codes such as pragmatism and positivism with codes derived in vivo from students' own language such as "creativity" or "knowledge of how to code." The final result is a thematic analysis that is derived from the participant's own language, but still connected to larger abstract epistemological notions in the philosophical literature. This aided with answering RQ3 in our study.

Advantages of this method include the multi-scale nature of the methods: epistemologies were derived at the macro level through a priori coding, which allowed us to connect ideas across interviews. On the other hand, discourse analysis at the micro-level dove into the syntactic choices used by these participants and helped us to understand how such choices reflect their personal epistemological foundations. Further, by using discourse analysis to follow our a priori epistemological coding with in vivo coding in participant language, we do not impose arbitrary or foreign theoretical machinery upon student experiences, but rather let the data inform us of how this machinery ingresses itself into our particular context. Disadvantages of this method are that the analysis stage is still tedious and time-consuming (with its multiple analytic approaches) and is not scalable to larger studies that may have hundreds of participants. However, we felt that this design with multiple analytic steps had the potential to effectively answer our research questions and triangulate findings within the data.

\section{Data collection and analysis}

To answer our research questions, we used an a priori/ deductive coding scheme (Saldaña, 2013) followed by discourse analysis (Gee, 2014) with six student interviews. Below, we detail the context of the study as well as the data collection and analysis procedures. This study was evaluated and approved by the Arizona State University IRB.

Six undergraduate students participated in the study from within the AME program. Student demographics which were self-reported by participants included $5 \mathrm{fe}$ male and 1 male participants, as well as race/ethnicities including white (2), Hispanic or Latino (2), Native American (1), and multiracial (1). The high representation of female students in our sample reflects the demographics of the AME program which has nearly 50\% female enrollment in the major overall. In Table 1, we present a table summarizing the participants' demographics as well as their capstone or other projects they described in the interviews.

We note that our sample size is small $(N=6)$, but this is not atypical for qualitative research where data is thick and rich for even one participant (Morse, 1994). We also acknowledge here that six participants represent approximately $15 \%$ of students in the capstone courses. Further, discourse analysis is a highly time-consuming qualitative research method analyzing language choice down to particular words or phrases (Gee, 2014), and thus is not particularly scalable to large studies. 
Table 1 Study participants' demographics and project descriptions

\begin{tabular}{|c|c|c|c|c|}
\hline Participant & Major and year & Gender & Ethnicity & Project description \\
\hline Paul & Senior, digital culture major & Male & Caucasian & $\begin{array}{l}\text { An EEG headband that records brain activity and sonifies them using granular } \\
\text { synthesis to novel audio to be listened to }\end{array}$ \\
\hline Dakoa & Junior, digital culture major & Female & $\begin{array}{l}\text { Native } \\
\text { American }\end{array}$ & $\begin{array}{l}\text { A motion reactive system where movement triggered audio effects and sounds } \\
\text { which correspondingly trigger lights and visualizations }\end{array}$ \\
\hline Sara & Senior, digital culture major & Female & Caucasian & $\begin{array}{l}\text { An interactive floor installation consisting of squares that light up with LEDs } \\
\text { and display visual information }\end{array}$ \\
\hline Maria & Senior, digital culture major & Female & $\begin{array}{l}\text { Hispanic } \\
\text { (Mexican) }\end{array}$ & $\begin{array}{l}\text { A 2D animation visualizing endangered animals to help raise public awareness } \\
\text { of these issues }\end{array}$ \\
\hline Anna & $\begin{array}{l}\text { Senior, computer science } \\
\text { major, minor in digital culture }\end{array}$ & Female & $\begin{array}{l}\text { Indian and } \\
\text { Swedish }\end{array}$ & $\begin{array}{l}\text { An augmented reality application that emulates the game "Battleship" to be } \\
\text { played on a tabletop with markers }\end{array}$ \\
\hline Miranda & Senior, digital culture major & Female & Hispanic & $\begin{array}{l}\text { Two projects: (1) an art piece about virtual/online dating (not fully realized) and } \\
\text { (2) an interactive room installation consisting of projected videos and } \\
\text { microphones that pick up words visitors say and change the projected videos } \\
\text { based on this input }\end{array}$ \\
\hline
\end{tabular}

Discourse analysis relies on interpretation, rather than objective and generalizable statements, and it is the depth of this interpretive analysis applied to smaller groups that it is valuable. We discuss these limitations in greater depth below.

A question that arises is what such a small number of participants can tell us. Are the findings from six generalizable/externally valid? Some studies, especially those informed by grounded theory, often rely on data saturation and use a moderate number of interviews $(20+)$ to achieve this. However, with especially small numbers of participants, researchers often strive for transferability, rather than generalizability (Lincoln \& Guba, 1985; Shenton, 2004). Tracy (2010) explains that "transferability is achieved when readers feel as though the story of the research overlaps with their own situation and they intuitively transfer the research to their own action" (p. 845). This means that we, as researchers, must provide a strong description of the context of our study, and our readers may ultimately determine the degree to which our findings may apply to their own contexts. We feel that 6-h-long interviews provided us with six unique views into students' experience with AME coursework; while it is certainly possible that others in the program had other experiences, these six provide us with a good foundation to begin thinking about how students epistemologically identify within such a program, especially considering these students' assorted backgrounds.

Participants were recruited from the AME capstone course and were chosen because the course is only taken by students approaching graduation; we felt that these students had ample experience with the program, completing art- and engineering-heavy projects. All students enrolled in the Spring 2018 capstone course were sent an email explaining the nature of the study as well as a demographic survey. Six responded and ultimately agreed to be interviewed. Semi-structured interviews were conducted by either Dr. Joshua Cruz or Dr. Suren Jayasuriya in a closed office space. Although one of the interviewers was AME faculty, he did not know any of the participants prior to interviewing. Interviews were recorded using a tape recorder and transcribed by hand.

Interviews began with simple "warm-up" questions, such as the amount of time they had spent in the program, to ease participants into more difficult and abstract questions (Kvale \& Brinkman, 2009), moving to questions and prompts about experiences and projects they remembered in their program and then to questions about the nature of knowledge itself. All data in this paper is presented with student pseudonyms in compliance with IRB. Our questions for the interview are listed in Table 2, bearing in mind that semistructured interviews allowed for the creation of new prompts and follow-up questions based on participant responses.

Coding of interviews occurred in two parts. First, two of the authors collected quotations from the interviews that they felt offered insight into student epistemologies, what we are terming "epistemologically rich passages." These passages are later highlighted in the "Results and findings" section of this paper. To determine these passages, individual researchers first looked through the transcripts with attention to instances when students mentioned knowledge/knowing, truth, differences in discipline, dispositions toward particular projects, and purpose of their projects. We felt that these topics had the potential to offer insight into implicit epistemologiesthat is, we used them as a model for staying sensitized (Charmaz, 2006) to ways of thinking that students described when approaching their coursework. We collaborated to reach agreement on those passages that we all felt might offer rich discussion. Then, we determined specific epistemological beliefs that were present in them. Saldaña (2013) suggests that at times one may develop a list of codes "to harmonize with [a] study's 
Table 2 Interview questions for the study protocol

\begin{tabular}{ll}
\hline Question & I'm particularly interested in your experiences in the capstone project (or a project you have worked on recently in AME). Could you tell \\
\hline 1 & me your story of your project, from selecting the project/being assigned the project to now? \\
3 & Can you describe what the problem or issue you are trying to solve? \\
4 & How much artistic knowledge and/or skills went into your project? \\
5 & What much engineering knowledge and/or skills went into your project? \\
6 & If you could conceptualize your project differently, how would you approach it?
\end{tabular}

conceptual framework, paradigm, or research goals" (p. 62). Our deductive coding scheme was a list of epistemological stances, elaborated above: positivism, empiricism, rationalism, representationalism, constructionism, skepticism, post-structuralism, and pragmatism. This scheme provided structure as we inferred epistemological stances based on the ways that students described their understanding of the nature of knowledge and approaches to problem solving. After discourse analysis of these passages, we returned and performed in vivo coding (Saldaña, 2013) to recast the a priori epistemological codes into codes in participants' own language.

Discourse analysis was used to better understand how student epistemological identities operated within the AME program. Discourse analysis helps us to understand "the way in which texts themselves have been constructed in terms of their social and historical situatedness" (Cheek, 2004, p. 1144). Further, discourse analysis may be used for questions regarding how individuals construct and present their identities within social settings (Gee, 2014). Given the importance of alignment between identity, epistemology (Demerath, 2012), and coursework in science (Conlin et al., 2015), as well as the potential for various epistemological frameworks to be adopted in the AME program, we wanted to better understand the ways that students situate themselves within the AME program epistemologically. For this study, we looked at the language that students used in those passages identified as epistemologically rich, using several tools from Gee's discourse analysis "toolkit, "specifically:

- Breaking the quotations into stanzas to make the interview data more manageable and to allow us to better look at the effects of individual words and smaller phrases. Breaks in lines happened at the level of meaning units, in our case, either words or phrases that presented a standalone image or idea (e.g., a person doing, an object being, an idea existing).

- Paying close attention to coordinating conjunctions, as these work to create parallels between ideas ("and/nor"), juxtapose ideas ("but/yet"), show contrast ("or"), or show logical progression and linkages between ideas ("for/so") and therefore help us to understand the mood and trajectory of statements.

- Examining deictic words and phrases to better understand how certain words are contextually contingent.

- Considering the motivation behind word choices to home in on specific meanings that participants may be attempting to articulate; this ties into the last analytic.

- Keeping in mind how utterances enact certain kinds of behavior and identity, especially given that epistemologies are also tied to how people think and do in the world (Demerath, 2012). This was especially important to us given that students readily positioned themselves as either artist or engineer during interviews, without prompting.

It should be noted here that there is no one way of performing discourse analysis, and like much qualitative research; it is an interpretive method (Gee, 2014). To establish credibility within our findings, we attempt to describe as clearly as possible our reasoning for interpreting the findings in the way that we do.

Further, Antaki et al. (2003) point out six common mistakes in discourse analysis, which they call under- or non-analysis through "(1) summary, (2) taking sides, (3) over-quotation or through isolated quotation, (4) the circular identification of discourses and mental constructs, (5) false survey, and (6) analysis that consists in simply spotting features" (p. 3). The first three issues we feel we avoid by offering a balance between participant quotations set into stanzas, rather than summary, and deep analysis of the way that words and phrases work together to make a particular kind of statement using the tools above. The fourth issue involves compiling quotations and making a claim that the speaker is drawing from a particular ideological (in our case, epistemic) discourse. A problem emerges when we do not explain the link between the use of language and the speaker's alignment to a larger discourse. As one of our research 
questions involves the way that participant language aligns them with a certain kind of social identity, we attempt to explain how certain language use corresponds to different epistemological camps. The fifth issue occurs when researchers attempt to generalize their findings to a larger population. Simply put, we do not see this as an issue because generalizability is not our goal as we have explained above. Again, we aim for transferability (Shenton, 2004), wherein we share individual experiences that provide future researchers with areas to examine more deeply and practitioners with potential concerns that they should be aware of within their own classes. Finally, Antaki et al. (2003) identify "spotting" as a form of nonanalysis, in which researchers simply recognize common rhetorical/speech patterns in language. In our piece, we pay less attention to speech patterns and more attention to what the language serves to do, as well as how it does it, related to participants carving out a particular identity for themselves.

\section{Results and findings}

Through our a priori coding, we identified several words and phrases used within interviews that we felt indicated epistemological positioning. Below, we examine the three most common epistemological alignments that we found in the data: constructionism, positivism, and pragmatism. We also describe some of the participants' most common words that we took to indicate the above epistemologies (interpretation, right/wrong, and working, respectively). This is important for two reasons. First, it provides greater clarity regarding our own coding scheme, and second, it provides a useful baseline for others who may wish to qualitatively study epistemologies of undergraduate students. We then provide a discussion on what we are terming "boundary epistemologies," or instances where participants suggested that they drew from multiple epistemological camps at once. Given length constraints, we attempt to provide the most relevant quotations and words for the common epistemological camps as indicated by participant language.

\section{(Social) constructionism/interpretation/creativity}

We understand social constructionism as an epistemology wherein truth is negotiated among members of a group and is "shaped by the cultural, historical, political, and social norms that operate within that context and time" (Darlaston-Jones, 2007, p. 19). One word that we saw as indicating this social constructionist approach was "interpretation," or variations of this word. This word is reflective of a constructionist viewpoint because it suggests first that knowledge is not absolute and second because it suggests that individuals rely on their own contexts to make sense of-or interpret-a piece of information that they receive (Staller, 2013).

Such interpretation was linked almost exclusively to artistic themes in students' projects. Paul, for instance, stated that different individuals could have a completely different understanding of his project, but because he conceptualized it as an artistic project, none of them would be wrong: "Because, like, art is open to interpretation" and understanding the project simply means being "able to think critically about it and, like, come to some sort of conclusion." Paul uses the phrase "some sort of conclusion" to refer to the aims of his project. "Some sort" is a noncommittal phrase and stands in opposition to a more definitive phrase such as "the conclusion." This suggests that Paul is more concerned with viewers using his project to think about an issue, although what and how they think about it does not have to be uniform. If it is the case that there is no uniform conclusion, it means that there is no ultimate right/ wrong conclusion, and we believe that this represents an openness to multiple truths. Additionally, Paul refers specifically to his beliefs about the truth when he suggests that in one of his projects, he "fudges the truth" (more on this in the border epistemologies subsection). Anna also describes a lack of concern with what is right and wrong in her own project. Such statements indicated that whether or not there exists absolute truth, participants felt that there was something to be interpreted by viewers/users of their projects. We understood such statements as reflecting a constructionist framework because within constructionism, truth is negotiated among members and there is no strict adherence to right/wrong. Knowledge itself is a construction based on the historical and social contexts of those who hold said knowledge.

Another word that we associated with constructionism was "creativity." The use of "creativity" was mentioned by all the participants, often in contrast to notions of a stable truth or knowledge. Dakoa described creativity as esthetic knowledge that is used when designing a product for others. In describing the creativity associated with web design, Dakoa mentioned that while there are many technical and pragmatic factors (such as coding, described within our "pragmatism" section), she considered artistic knowledge as "being creative, adding color, changing fonts," which she further described as "personal" and "public work." Often, personal and public are contrastive terms, but by saying that creativity entails both, Dakoa suggests that both are linked. If it is both, then creativity begins with the artist, who creates art for other individuals (public) to interpret. Similarly, Sara described a project manipulating video playback with Playdoh. In this case, she understood the project as requiring little technical knowledge to function; however, because 
the project was highly interactive, she claimed that it was creative and "more about the arts." As individuals interacted with it, they were allowed to construct their own meaning based on the video playback which was, itself, contingent upon the various ways that they might manipulate the Play-doh. Both Sara and Dakoa indicate that creativity is tightly linked to artistry, and when the work of art is developed, it is then given to a public which then may construct meaning from the project.

Overall, participants understood that as individuals interacted with their projects, each would construct a different meaning. Our participants ultimately suggested that this was because the creative nature of their projects meant that no interpretation was necessarily correct. Rather, there exists an interplay between the viewer and the project itself where the truth that they create may be multiple.

\section{Positivism/"right" and "wrong"}

On the other hand, positivism indicates a belief in a stable and absolute truth that transcends human interpretation (Darlaston-Jones, 2007). We saw various indicators of positivistic approaches to knowledge, including deference to expert knowledge. Anna, for instance, stated that when she had a problem, she "talked to [her professor], since he has some knowledge of AR [augmented reality]." On the other hand, Maria described being hesitant to speak to certain professors because she felt that their knowledge did not align with her own interests, and she was concerned that she would be told that her project was incorrect. In yet another instance, Dakoa described instances of having to learn code and asking the teacher for help because she struggled to develop the "right" syntax when coding, and she enjoyed being able to see what she did "wrong" by going over her codes. In all of these cases, knowledge is something to be possessed by certain individuals who specialize in holding such knowledge. The use of a right/wrong binary (Maria, Dakoa) or professors as holders of specific knowledge (Anna) suggests that such knowledge is associated with a transcendental truth. It is possible that asking for an expert opinion could be a matter of constructing knowledge together: had our participants couched such discussions in terms of, say, spit balling, weighing ideas, or finding direction for their projects, we certainly would have understood these as negotiations where truth has a degree of relativity (constructionism). However, in these cases, students saw knowledge as a binary between right and wrong rather than a negotiation. This binary is also observed in Perry's (Perry Jr., 1999) scheme of cognitive development within college students: often (especially) lower division college students believe that experts possess correct knowledge, what Perry refers to as a right/wrong dualism. Under
Perry's scheme, it is only through experience that students can learn to question the assertions of such authorities and develop a more relativistic stance toward knowledge.

Additionally, we also observed relaxation of positivistic beliefs, which we coded as post-positivism. Anna, who earlier in the interview had deferred to knowledge held by her professor, also stated “Umm, I mean,/ I don't think there is always a right answer/ of what makes something usable,// but there are certainly guidelines/ maybe that we can try to find." This statement shows that at this moment, Anna is relaxing the notion that there is a single right answer (positivism), but believes there are still possibilities to arrive at something that is correct (post-positivism) (Staller, 2013). The use of "guidelines" suggests that there are still design principles or sign markers that indicate an individual is headed toward a correct answer.

\section{Pragmatism/"working"/technicality}

Pragmatism is the belief that knowledge is derived from its utility or explanatory/predictive power for current and future actions. This is the most common epistemic belief we expect to see in engineering where focus is often on an end product or outcome. We saw several instances of pragmatic approaches to projects in our data. Anna mentioned "I would say/ if you understand something,/ you can teach it to other people,/ you can take it outside,/ take it on your own/ and apply it to any,/ you understand it." Here, the language of application, "take it," and teaching focuses on the utility of the understanding, its transferability to other domains that indicates a pragmatic epistemology at this moment. Students seemed to be drawn to this pragmatic approach, as Dakoa mentioned "sometimes it's kind of fun/ to figure out what you did wrong/ or um, see like what's not working/ and what is" with reference to performing computer coding as part of her project. The use of "working" was a common indicator for a pragmatic criterion for students' evaluation for engineering skills, as many students did not seem to return to the engineering side of their project after they got something working. We did not see many instances of linguistic indicators for pragmatism when students were describing the creative or artistic side of their projects.

In fact, "technical knowledge" was often used to indicate what we understood to be a more pragmatic stance, but it was often contrasted to "creative" or "artistic" knowledge. For instance, as mentioned above, Dakoa acknowledged that the technical side of website design is what "[gets] that working." We additionally see this with Miranda, who like Dakoa, describes the technical versus creative as a kind of process. One must understand the technical and functional side of a project before 
addressing creative aspects: "as you learn more techniques, you can be more creative." But, as both technique and creativity come together, the project becomes "best." We understand technicality in this case to be a kind of tool that allows for creative aspects within the project to function creatively.

\section{Boundary epistemologies}

Overall, students used a number of epistemologies as they engaged in their studies at the intersection of art and engineering, most notably positivism, constructionism, and pragmatism. Individual students did not use one type of epistemology solely, but rather shifted their understanding of what knowledge they deployed and utilized in context for each project/assignment. To better describe this concept, we employ the concept of "boundary epistemologies," adapted from Star and Griesemer's (1989) idea of "boundary objects." A boundary object is an information that might be used or understood differently from discipline to discipline. Just so, a boundary epistemology is a way of thinking or constructing knowledge that might receive different value from discipline to discipline. Students' epistemological approaches must be malleable to fit across the boundaries that they are required to cross as disciplines come together, allowing students to understand knowledge in different ways as they interact among disciplines. Below, we provide four examples of this epistemological bordering as students began to describe learning art- and engineering-based tasks within the AME program. We bold italicize the epistemologically oriented words within the results for two reasons: first, we believe it helps readers to easily locate different epistemologies we found in the data. Second, we hope it helps to represent the kaleidoscopic nature of epistemologies present, and how these are bordered, boundaried, fluid, and shifting depending on the context. For instance, Paul stated that, "with engineering, it seems a lot easier because it's like just a matter of being taught it and doing it enough to where you're, you don't have to think about it. Understanding in an artistic perspective, though, is harder to teach because I think it requires critical thinking skills."

The above quotation brings two epistemological stances into conversation with each other. Paul recognizes the dominant, positivist epistemology that underlies much engineering work, seeing it as "easier" because there is a stable truth to learn: that truth exists, it must be integrated into one's existing knowledge structure, but it does not need to be critically examined because it is a transcendental form of knowledge. On the other hand, Paul contrasts this stable knowledge to that of art, which is interpretivist and "requires critical thinking" to approach. Paul elaborates on the idea of critical thinking, describing it as thinking "about, like, what you're creating and what it conveys." Paul sees art as a rhetorical negotiation between the product and the way that the audience will interpret it-it requires that one consider one's social environment as well as the message that one wants to produce through artistic representation. This anticipates a constructionist epistemology, one wherein meaning and knowledge are a construction between social entities. While these may seem like disparate ideas (a positivistic and stable knowledge in engineering; a representational and socially constructed knowledge in art), Paul later described blending the two: "strictly with like an engineering project you just have to think about whether it's going to work or not...in [a AME] project, it's a little bit of both, you have to think about what you're trying to convey but also if the tech is going to work."

The concept of a project "working" is suggestive of what Psycharis (2018) refers to as a "practical epistemology," which is not concerned with the nature of knowledge and reality per se, and acknowledges that a product that can only work under a framework where certain facts are non-negotiable; there is a truth that must be assumed for engineering projects to work, which is simply practical for Psycharis. At another level, as indicated by the conjunction "but," which serves to create a juxtaposition with the working project, Paul wishes to express a message. In this case, the student must adopt a more socially constructive viewpoint, one where knowledge/truth/meaning is negotiated among members of a group.

We see epistemological bordering described by several of our participants. Maria, describing her desire to get an arts-based job such as animation, stated "but to be realistic, I want to get a real job. And, I want to get up to date. What's going on out there... I know there are some jobs that say, if I want to be an animator, I need to know a little bit of coding. Or I have to be realistic that I can't."

To better situate this quotation, it is important to note that Maria identified as an artist, one who relied primarily on creativity to solve her coursework. Throughout the interview, Maria made reference to the fact that she saw herself as an artist despite the fact that she "would love to be an engineer." She acknowledged that she simply did not have the mind of a mathematician or engineer; however, there was a clear respect for positivistic and pragmatic knowledge (as suggested by her need for "a little bit of coding" even as an animator), and she saw that type of knowledge as helping her to secure a job and "be realistic." The word "realistic" itself suggests an onto-epistemological view of a static type of reality that exists in math-based disciplines (positivism) but is not present in arts-based disciplines. The word "but" implies a juxtaposition to her statement that she wanted a job 
that was highly creative, wherein "reality" as unartistic and uninterpretable serves as this juxtaposition. While she strongly identified as an artist, she felt that practically, she had to employ a more transcendental understanding of reality than an artist might. In this way, there was a negotiation between Maria's own interest in art (constructionism/interpretivism) and some practical reality adopted by engineers, one which she mentioned needing to better access several times throughout the interview.

A third example of this epistemological border crossing can be found in Miranda, who explored the representing connotations and feelings associated with words. Miranda's concept for the project was to place monitors around a room with microphones that would pick up the words that people were saying. The software would then identify the words and play back videos that others created associated with those words. Here, her interest was markedly post-structural-words and meanings among groups are necessarily unstable and may reference different ideas depending upon the user of the word-and throughout the interview, she made reference to having an interest in how people mediate difficult-to-describe emotions to one another. On the other hand, for her project to work, she needed to rely on "coding and programing to get everything, kind of reacting together" which she later described as "concrete." Ultimately, according to Miranda, assessing whether or not everything is reacting correctly is determined by whether or not it works. In this case, we see a blending of three epistemologies, one that is post-structural in its understanding of language but still informing a more artistic, representational goal, as well as a more "concrete" empirical approach that makes possible these representational elements. Miranda knows that she has done what she wants to do when "it works," a pragmatic approach, one reminiscent of the practical epistemology referred to by Psycharis (2018). There is not a concern for the "truth" per se, but the way that various discrete epistemological approaches come together to create both a representation and something that works within the parameters of both a social and a technical reality.

A final consideration is how Paul described the way that "truth" itself must be negotiated when engineering and art come together. In describing a group project in which he created a ball that played music when rolled, he stated:

That specific project kind of falls in the middle between art and research. Because our original intention was completely art, we just wanted to be able to like make cool music. But, like, given how complicated that was and, like, our alternative solution it ended up going more into the research side of things... Yeah. And if, our code also wasn't exactly perfect. As far as, like, doing the research stuff because, like, we still wanted, like, a sound that was, like, pretty and, like, nice to listen to. So the code was kind of fudged a little bit so that it could sound prettier. And that, like, kind of removed the, the truth, the trueness behind the research stuff. So yeah it's kind of in the middle and it could go either way.

Paul did not elaborate on what it means to remove the truth from the code or the research, but we infer that he adopted a positivist/rationalist epistemological stance when referring to his engineering research, which he contrasts to being "completely art" using the conjunctive "but." For the code to be true, it had to look a particular way, and the numbers had to come together to form a "true" answer. Like the first example, however, the project had a performative aspect; it had to produce pleasant music, and an audience had to be considered, which becomes a result of imperfect coding (the conjunction "so" suggests this cause and effect). Once this became a consideration, a positivistic truth became less important when compared to the affective response that the music might produce in its listeners, a more constructionist concern. As such, the "truth" had to be "fudged."

We see how, in the context of a STEAM program, different conceptions of what is true and what is knowledge become valuable to different ends. While a pragmatic, positivist, or rationalist epistemology might be useful in informing physical design or coding, knowledge of emotional reactions, intuition about human behavior, and non-empirical value (axiological) judgments informed other aspects of these engineering projects, particularly when considering the artistic side. As such, students had to fluidly move between epistemologies, sometimes weighing them against each other to meet certain ends, sometimes fudging or changing midproject what counts as "truth." As Paul put it, when developing an arts- and engineering-based project, "I think, like, just being aware of different aspects, even if it's not what you think you know you have to test both sides, you have to think of everything, think how it all effects something." This "think of everything" necessarily entails a crossing of epistemological boundaries, testing the $\boldsymbol{e m}$ pirical and positivistic aspects of the project, but considering how the project might be integrated, constructed, and interpreted within a social environment.

\section{Student identification with arts and/or engineering}

This epistemological boundary crossing proved difficult for some students because they perceived certain kinds 
of knowledge as taking precedence in the program. This perceived prioritization of knowledge, always characterized as empirical/positivist/rationalist knowledge, forced students to make decisions that they may not have otherwise made and, in some cases, led them to characterize themselves as deficient. Due to the lengthy nature of discourse analysis, we provide four examples of this. Miranda characterized engineering and art as being concerned with the tangible and intangible, respectively. When asked if engineering has any intangible qualities, she stated:

I think there are, and I think of it as more of, like, a problem solving kind-of-way though, where I feel like personally with art, there's no one answer to something, and I feel like that can be applied to a lot of things that are done in the engineering aspects of AME, but I feel like for me it takes a much higher level of skill to get to that point where you can intuitively or just know what options are available that are also considered correct options. So I think the level I'm at, no, because I need a result, and so I need to know which is the correct way to do something, but I think if, once I delve more into it and am more comfortable with using different types of things, then it becomes what could be the best, and then it becomes something that has its own character to it.

At another point in the interview, Miranda identified as an artist rather than an engineer; she prioritized art in her life. However, the language she uses to describe her experience with engineering ("correct options," "I need a result," "the correct way," "what could be best") suggests that she sees a necessity to adopt a more positivistic/rationalist mindset. Miranda, at least "at the level [she is] at," is unable to apply an artistic approach to engineering because of disciplinary constraints (needing a "correct" result). Even at a higher level that Miranda alludes to, where "you can just intuitively know which is the correct way," the artistry comes from (empirical) experience working within engineering. The message that Miranda conveys seems to be clear: there is a kind of correct truth in engineering that cannot be ignored. Moreover, this truth is often at odds with more intangible ways of knowing. This observation dovetails nicely with the previous example, wherein bringing an artistic way of thinking "fudges" or "removes the trueness" behind engineering designs.

However, Miranda used language within the interview that showed both a desire for and a feeling of deficiency in this type of "correct" knowledge. She stated several times throughout the interview that she would like a greater grasp of engineering knowledge; however, she additionally identified a heavy engineering focus within the program: "I would say that for right now I honestly feel like AME is specifically for me at least, focusing more on the engineering kind of side of things, and then kind of not expecting you to know the artistic side."

If it is the case that engineering and the kind of knowledge/approach associated with engineering is the primary focus of her coursework, then we might expect that she, who identifies as an artist, might feel deficient. While students had to negotiate epistemological borders, they also had to come to terms with types and use the kinds of knowledge associated with engineering, lest their product be untrue (Paul) and therefore deficient (Miranda).

Turning attention more closely to Paul, who also identified as an artist coming to the AME program, the theme of epistemological struggle recurred throughout his interview. At one point, he compared himself to those that he perceived as identifying as engineers: "I feel like for them it's like really easy because it's, it's something it's a skill you know, like, for them it's something like, oh yea easy cake. But for me, it's like, 'What is it? What is that?' They're already going to the looping, and I'm still in the 'But, why?" In this case, Paul's deficiency in being able to approach problems as an engineer marks him as an outsider. There is a clear me/them mentality that pervades the second half of his conversation, but it is especially clear in the final two stanzas. He refers to "it" (knowledge of engineering) as a "skill," but it is a skill "for them" (engineering students). Using the word "them" along with the juxtaposing "but" suggests that Paul sees himself in contrast to engineers. The word "skill" suggests that what these engineers are doing exists beyond abstract knowledge. Instead, it involves a practical application of knowledge, but Paul is unable to move into this realm of practicality with his fellow students: "they're already/ going to the looping,/ and I'm still in the/ "But, why?" This may also be a result of his identity as an artist, which he describes elsewhere in the interview as being concerned less with the practical ("doing the looping") as it does the abstract and representational (“But, why?"). His closing lines further show the me/them mentality that pervades much of his interview. In this case, he is being left behind by those with more "skill" than him. In sum, what we see is a lack of identification as an artist in what Paul perceives to be a discipline that is primarily engineering. This is not to say that he resents the program, but he feels some degree of deficiency and perhaps shame in his inability to master both the artist and engineering aspects of his program. He clearly sees a value in engineering, and throughout the interview, he continually made reference to wanting engineering knowledge, enough so that at one point he apologized for his lack of knowledge. The issue is simply 
that he does not understand the material, a problem that through discourse analysis; we find he attributes to his personal and epistemological identity.

Both Miranda and Paul explained that they saw themselves as artists coming into the AME program. Some students, on the other hand, had stronger engineering backgrounds, and their experience was largely positive. Sara for instance, transferred from an electrical engineering program, and for her, the AME program was "freeing." She described a project wherein she designed a periodic table of elements that individuals could step on. As individuals stepped on different elements, a speaker would provide information about the element. She liked the course that included this assignment because:

Before taking the class, I wasn't really, I just, I wasn't thinking, like, big enough or I wasn't thinking of different possible ways to do something. There's one way to do this. That's the best way. And after that class, there's tons of ways you could do things, like, there's no, like, limit. And you just like think broader about things.

Like Miranda, we see the idea of "the best way." Before taking an AME course, she maintained that there were specific ways to go about solving problems: positivistic, single answers. We see "limit" appear in her language, and in two other instances, she refers to the "creative freedom" that the program offered her. Words such as these suggest that she felt stifled, perhaps even imprisoned in her former program, as her former program is her point of comparison. Additionally, phrases like "not big enough" and "broader things" apply the metaphor of size/scope to the concept of ideas. This ties closely to the idea of freedom that she feels; if we imagine the scope of ideas as an area of large size, it provides her a larger area to explore, or, in the domain of ideas, more possibilities, a fact which she enjoyed.

Others with a strong engineering background felt similarly about the freedom offered by the program. For instance, Anna compared the program with her background in computer science: "I think some of these classes are a bit easier than CS classes, but because I have that background in programming so I have that experience going in. I think they are more fun... because it's not right or wrong, like it works, but you can spend as much time as you want to make it look good." In both Sara and Anna's experience, having a background in technical or engineering knowledge seems to make learning easier. As with earlier examples, we see that Anna is less concerned about what is right or wrong, and truth is a more pragmatic or practical concern about what "works." But what is interesting is the final lines: "you can spend as much time/as you want to make it look good." Like Paul, there may be some competition between making a project work and the esthetic qualities of the project. However, while Paul described esthetic concerns as "fudging" the truth, Anna does not seem to address truth or knowledge at all here-instead, the esthetic concern is simply a matter of making it "look good." The fact that the esthetic side of her work is "fun" and "easy" is not bad in and of itself, but the fact that it is relegated simply to "looking good" suggests that knowledge in the artistic sphere is superficial.

These four examples provide representation from students who identified more strongly as artists and some who identified more strongly as engineers. Those who identified as artists seemed to struggle to integrate positivist ways of knowing into their identities, and they used language that was indicative of deficiency. On the other hand, students who felt comfortable with positivist/rationalist ways of knowing enjoyed the creative aspects of integrating art into scientific discourse. Demerath (2012) would support this understanding: students with stronger engineering backgrounds felt comfortable because their ways of knowing were clearly valued and encouraged, and they had only to integrate artistic approaches into their work. On the other hand, students who identified as artists had to shift their entire way of understanding the world to better fit into a community that values positivist/rationalist approaches above others.

\section{Conclusions}

In this piece, we used a priori coding paired with discourse analysis to answer the following questions:

RQ1: What implicit epistemologies can be discerned when students describe their approach to coursework that is a blending of arts and engineering?

RQ2: In the absence of specific vocabulary to indicate epistemological orientations, what language do students use that reflects their espoused epistemologies?

RQ3: How do students' personal beliefs and epistemological alignments inform the way that they navigate their AME coursework?

Our findings indicate that students have to carefully navigate between epistemological worlds in a program that blends art and science, which helps answer RQ1. Further, students receive messages about what kinds of knowledge should take priority as demonstrated by the border epistemologies, regardless of whether these messages are intentional or not. In some cases, students can de- or undervalue the knowledge and beliefs with which they enter such a program, and subsequently feel pressure to adopt stronger positivist stances as they traverse their coursework. We believe that this may be a result of 
the fact that student identities and epistemologies are closely linked to students. Those who identify as artists may draw more heavily from the epistemological norms within artistic disciplines, and the same might be said for engineering students. According to Demerath (2012), students may experience alienation as they are put into positions where they must interact with and adopt epistemologies with which they are less familiar or comfortable. This is especially important to consider as we ask students with disciplinary interests to work together in groups. While we did not explore group dynamics in this study, future research may examine the ways that students come together (or fail to) when they interact with peers who hold different epistemological identities than their own.

This suggests that within science-based programs, especially those underpinned by transdisciplinary values, instructors need to be careful about the types of messages they convey, perhaps intentionally adopting a viewpoint that, like the students, allows these epistemologies to border one another. For those students who come from more artistic persuasions, professors need to encourage and value the creativity and expressivism that they bring to the table, helping them to integrate positivistic and empirical models into their frameworks of knowing. On the other hand, students from positivistic backgrounds did not indicate that they needed substantial help when approaching the artistic side of their program; instead, they were grateful for the freedom that such an approach allowed. Thus, it also might be useful for traditional engineering programs to offer students the freedom to leverage artistic creativity in their work. While we did not set out to understand the degree to which professors may influence student adoption of different epistemologies, it became clear to us that students see professors as knowledge holders. As discourse analysis may also be used to examine hierarchies and power differentials, a revealing future study may focus on the discourse used in classrooms and between students and instructors to determine how instructors might influence epistemological choices.

The introduction of border epistemologies to describe context-specific knowledge parallels other researchers' findings, which have observed context-specific knowledge and further branch into concepts such as cognition, aims, and ideals (Chinn et al., 2014; Faber \& Benson, 2017). This is not a surprising result necessarily, but the elucidation of this bordering in the discourse/linguistic analysis shows that multiple epistemologies can be present in a particular context, and students navigate this epistemic landscape while integrating arts and engineering. This was particularly apparent in the discourse used by students that was the focus of RQ2, particularly their use of terms such as "right/wrong," "creativity," and "technicality."
An important question is whether these border epistemologies are necessary for a program that aims at transdisciplinary integration between arts and engineering. As stated earlier, we adopt the definition of "transdisciplinary" as the synthesis of tools and knowledge from different domains of expertise so that they are no longer recognizable by any single domain (Lattuca et al., 2004). Why then do we not see this fusion or synthesis in the epistemologies of students themselves? One could argue that boundary epistemologies are these fusions, but they occur in temporally fast time frames with a short half-life before the epistemologies are split again and disassociate from one another. We think it is difficult for students to form a cohesive epistemology that encompasses all the integration possibilities between arts and engineering. Rather, these are emergent phenomena, and possibly like transdisciplinary work itself, easily can slide back into inter- or multi-disciplinary labels if analyzed or dissected too carefully by an observer.

The findings from this study can lead to implications for the design and teaching of STEAM in the future. While our findings are relevant primarily for the engineering education research community, they could potentially be applied in the future to other discipline-based education research areas in physics, chemistry, etc. For instance, the awareness of different epistemological stances and switching held by students is useful to develop design exercises and mentoring feedback to accommodate these viewpoints. It is important to not default into positivistic evaluations for student projects especially when students spend time and effort to coconstruct the epistemic foundations of their project with their teammates or the audience they wish to engage. Further, the discourse analysis findings in RQ3 can help inform how students discuss their own knowledge when reflecting on their project, and can help instructors identify the new skills and conceptual frameworks that students develop over the course of the capstone from these reflections.

\section{Abbreviations}

AME: Arts, media, and engineering; DC: Digital culture; STEAM: Science, Technology, Engineering, Arts, and Mathematics; STEM: Science, Technology, Engineering, and Mathematics

\section{Acknowledgements \\ The authors would like to thank all the student participants who were interviewed for sharing their stories. In addition, the authors thank Madeleine} Jennings for the feedback on the project ideas.

\section{Authors' contributions}

SJ conceptualized the study and supervised the project team. JC and SJ contributed to the data collection. JC and NB contributed to the data coding and analyses. JC and SJ wrote the manuscript and revisions. NK helped review the drafts and contributed to the manuscript revisions. All authors read and approved the final manuscript. 


\section{Funding}

This work was supported by NSF EEC-1830730 as well as support from the Herberger Institute for Design and the Arts at Arizona State University.

\section{Availability of data and materials}

The interview protocol used during the current study is available from the corresponding author on reasonable request. The datasets are not available due to IRB restrictions.

\section{Declaration}

\section{Competing interests}

The authors declare that they have no competing interests.

\section{Author details}

${ }^{1}$ Texas Tech University, Lubbock TX 79409, USA. ${ }^{2}$ Arizona State University, Tempe, AZ 85281, USA.

Received: 16 June 2020 Accepted: 1 April 2021

Published online: 13 April 2021

\section{References}

Antaki, C., Billig, M., Edwards, D., \& Potter, J. (2003). Discourse analysis means doing analysis: A critique of six analytic shortcomings. Athena Digital: Revista de Pensamiento e Investigacion Social, 3(3), 14-35. https://doi.org/10.5565/ rev/athenea.64.

Bhaskar, R. (1997). A realist theory of science. Classics Series. Verso.

Buehl, M. M., Alexander, P. A., \& Murphy, P. K. (2002). Beliefs about schooled knowledge: Domain specific or domain general? Contemporary Educational Psychology, 27(3), 415-449. https://doi.org/10.1006/ceps.2001.1103.

Carberry, A. R., Lee, H. S., \& Ohland, M. W. (2010). Measuring engineering design self-efficacy. Journal of Engineering Education, 99(1), 71-79. https://doi.org/1 0.1002/j.2168-9830.2010.tb01043.x.

Charmaz, K. (2006). Constructing grounded theory: A practical guide through qualitative analysis. Sage Publications.

Cheek, J. (2004). At the margins? Discourse analysis and qualitative research Qualitative Health Research, 14(8), 1140-1150. https://doi.org/10.1177/104 9732304266820

Chen, L., Xu, S., Xiao, H., \& Zhou, S. (2019). Variations in students' epistemological beliefs towards physics learning across majors, genders, and university tiers. Physical Review Physics Education Research, 15(1). https://doi.org/10.1103/ PhysRevPhysEducRes.15.010106.

Chesky, N. Z., \& Wolfmeyer, M. R. (2015). Philosophy of STEM education: The cultural and social foundations of education. Palgrave Macmillan. https://doi. org/10.1057/9781137535467.

Chinn, C. A., Rinehart, R. W., \& Buckland, L. A. (2014). Epistemic cognition and evaluating information: Applying the AIR model of epistemic cognition. In D. Rapp, \& J. Braasch (Eds.), Processing inaccurate information: Theoretical and applied perspectives from cognitive science and the educational sciences, (pp. 425-453). MIT Press.

Conlin, L. D., Richards, J., Gupta, A., \& Elby, A. (2015). "Bring it on": Explaining persistence in science at the intersection of identity and epistemology. arXiv preprint arXiv:1502.04421. https://arxiv.org/pdf/1502.04421.pdf.

Creswell, J. W., \& Creswell, J. D. (2018). Research design: qualitative, quantitative, and mixed methods approaches, (5th ed., ). SAGE.

Cunningham, J. W., \& Fitzgerald, J. (1996). Epistemology and reading. Reading Research Quarterly, 31(1), 36-60. https://doi.org/10.1598/RRQ.31.1.3.

Darlaston-Jones, D. (2007). Making connections: The relationship between epistemology and research methods. The Australian Community Psychologist, 19(1), 19-27.

Demerath, L. (2012). Explaining culture: The social pursuit of subjective order. Lexington Books.

Dolberry, M. E. (2015). From "they" science to "our" science: Hip hop epistemology in STEAM education [Doctoral dissertation, University of Washington].

Douglas, H. (2016). Values in science. In P. Humphreys (Ed.), The Oxford Handbook of Philosophy of Science, (pp. 619-630). Oxford UP. https://doi.org/10.1093/ oxfordhb/9780199368815.013.28

Dreyfus, B. W., Hoehn, J. R., Elby, A., Finkelstein, N. D., \& Gupta, A. (2019). Splits in students' beliefs about learning classical and quantum physics. International Journal of STEM Education, 6(31). https://doi.org/10.1186/s40594-019-0187-y.
Elby, A. (2001). Helping physics students learn how to learn. American Journal of Physics, 69(7), S54-S64. https://doi.org/10.1119/1.1377283.

Elby, A., Macrander, C., \& Hammer, D. (2016). Epistemic cognition in science. In I. Bråten, J. Greene, \& W. Sandoval (Eds.), Handbook of Epistemic Cognition, (pp. 113-127). Routledge.

Ertas, A., Maxwell, T., Rainey, V. P., \& Tanik, M. M. (2003). Transformation of higher education: the transdisciplinary approach in engineering. IEEE Transactions on Education, 46(2), 289-295. https://doi.org/10.1109/TE.2002.808232.

Faber, C., \& Benson, L. C. (2017). Engineering students' epistemic cognition in the context of problem solving. Journal of Engineering Education, 106(4), 677-709. https://doi.org/10.1002/jee.20183.

Figueiredo, A. D. (2008). Toward an epistemology of engineering. In 2008 Workshop on Philosophy and Engineering, The Royal Academy of Engineering, London.

Firestone, W. A. (1993). Alternative arguments for generalizing from data as applied to qualitative research. Educational Researcher, 22(4), 16-23. https:// doi.org/10.3102/0013189X022004016.

Gee, J. (2014). How to do discourse analysis: A toolkit. Routledge. https://doi.org/1 $0.4324 / 9781315819662$

Giere, R. N. (2010). Scientific perspectivism. University of Chicago Press.

Greene, J. A., Torney-Purta, J., \& Azevedo, R. (2010). Empirical evidence regarding relations among a model of epistemic and ontological cognition, academic performance, and educational level. Journal of Educational Psychology, 102(1), 234-255. https://doi.org/10.1037/a0017998.

Greene, J. C. (2012). Engaging critical issues in social inquiry by mixing methods. American Behavioral Scientist, 56(6), 755-773. https://doi.org/10.1177/0002 764211433794

Guyotte, K. W., Sochacka, N. W., Costantino, T. E., Kellam, N. N., \& Walther, J. (2015). Collaborative creativity in STEAM: Narratives of art education students' experiences in transdisciplinary spaces. International Journal of Education \& the Arts, 16(15), 1-38.

Halloun, I., \& Hestenes, D. (1996). Views about science survey: VASS. In Sociology Paper presented at NARST, St. Louis, Missouri.

Halloun, I., \& Hestenes, D. (1998). Interpreting VASS dimensions and profiles for physics students. Science \& Education, 7(6), 553-577. https://doi.org/10.1 023/A:1008645410992.

Henriksen, D. (2014). Full steam ahead: Creativity in excellent stem teaching practices. The STEAM Journal, 1(2), Article 15. https://doi.org/10.5642/steam.2 0140102.15.

Henriksen, D., Mehta, R., \& Mehta, S. (2019). Design thinking gives STEAM to teaching: A framework that breaks disciplinary boundaries. In M. Khine, \& S. Areepattamannil (Eds.), STEAM education. Springer. https://doi.org/10.1007/ 978-3-030-04003-1_4

Hofer, B. K. (2001). Personal epistemology research: Implications for learning and teaching. Educational Psychology Review, 13(4), 353-383. https://doi.org/10.1 023/A:1011965830686.

Hofer, B. K., \& Pintrich, P. R. (1997). The development of epistemological theories: Beliefs about knowledge and knowing and their relation to learning. Review of Educational Research, 67(1), 88-140. https:/doi.org/10.3102/00346543067001088,

Kvale, S., \& Brinkman, S. (2009). InterViews: Learning the craft of qualitative research interviewing, (2nd ed., ). Sage.

Lattuca, L. R., Voigt, L. J., \& Fath, K. Q. (2004). Does interdisciplinarity promote learning? Theoretical support and researchable questions. The Review of Higher Education, 28(1), 23-48. https://doi.org/10.1353/rhe.2004.0028.

Lincoln, Y., \& Guba, E. G. (1985). Naturalistic inquiry. In Naturalistic inquiry. Sage.

Maeda, J. (2013). STEM + art= STEAM. The STEAM Journal, 1(1), Article 34. https:// doi.org/10.5642/steam.201301.34.

Marra, R. M., Palmer, B., \& Litzinger, T. A. (2000). The effects of a first-year engineering design course on student intellectual development as measured by the perry scheme. Journal of Engineering Education, 89(1), 39-45. https:// doi.org/10.1002/j.2168-9830.2000.tb00492.x.

Montfort, D., Brown, S., \& Shinew, D. (2014). The personal epistemologies of civil engineering faculty. Journal of Engineering Education, 103(3), 388-416. https:// doi.org/10.1002/jee.20050.

Morse, J. M. (1994). Designing funded qualitative research. In N. K. Denizin, \& Y. S. Lincoln (Eds.), Handbook of Qualitative Research, (2nd ed., ). Sage.

Morse, J. M. (2010). Simultaneous and sequential qualitative mixed-methods designs. Qualitative Inquiry, 16(6), 483-491. https://doi.org/10.1177/107780041 0364741

Morse, J. M., \& Niehaus, L. (2009). Principles and procedures of mixed methods design. Left Coast Press. 
Oner, A. T., Nite, S. B., Capraro, R. M., \& Capraro, M. M. (2016). From STEM to STEA M: Students' beliefs about the use of their creativity. The STEAM Journal, 2(2), Article 6. https://doi.org/10.5642/steam.20160202.06.

Osbeck, L. M., \& Neressian, N. J. (2017). Epistemic identities in interdisciplinary science. Perspectives on Science, 25(2), 226-260. https://doi.org/10.1162/ POSC_a 00242.

Paulsen, M. B., \& Wells, C. T. (1998). Domain differences in the epistemological beliefs of college students. Research in Higher Education, 39(4), 365-384. https://doi.org/10.1023/A:1018785219220.

Perry Jr., W. G. (1999). Forms of intellectual and ethical development in the college years: A scheme. Jossey-Bass Higher and Adult Education Series.

Psycharis, S. (2018). STEAM in education: A literature review of the role of computational thinking, engineering epistemology, and computational science. Scientific Culture, 4(2), 51-72. https://doi.org/10.5281/zenodo.121456.

Redish, E. F., Saul, J. M., \& Steinberg, R. N. (1998). Student expectations in introductory physics. American Journal of Physics, 66(3), 212-224. https://doi. org/10.1119/1.18847.

Rikakis, T., Spanias, A., Sundaram, H., \& He, J. (2006, October). An arts, sciences and engineering education and research initiative for experiential media. In Proceedings. Frontiers in Education. 36th Annual Conference, (pp. 13-18). IEEE.

Rogers, P., \& Freuler, R. J. (2015, June). The "T-shaped" engineer. ASEE Annual Conference \& Exposition, Seattle, WA, June. doi: https://doi.org/10.18260/ p.24844

Rowlands, S., \& Carson, R. (2001). The contradictions in the constructivist discourse. Philosophy of Mathematics Education Newsletter, 14, 1-15.

Saldaña, J. (2013). The coding manual for qualitative researchers. Sage.

Schommer, M. (1990). Effects of beliefs about the nature of knowledge on comprehension. Journal of Educational Psychology, 82(3), 498-504. https://doi. org/10.1037/0022-0663.82.3.498

Schön, D. A. (1983). The reflective practitioner: How professionals think in action, (1st ed., ). Temple Smith.

Sharma, S., Ahluwalia, P. K., \& Sharma, S. K. (2013). Students' epistemological beliefs, expectations, and learning physics: An international comparison. Physical Review Special Topics- Physics Education Research, 9(1), 1-13. https:// doi.org/10.1103/PhysRevSTPER.9.010117.

Shenton, A. K. (2004). Strategies for ensuring trustworthiness in qualitative research projects. Education for Information, 22(2), 63-75. https://doi.org/1 0.3233/EFI-2004-22201.

Sochacka, N. W., Guyotte, K., \& Walther, J. (2016). Learning together: A collaborative autoethnographic exploration of STEAM (STEM+ the arts) education. Journal of Engineering Education, 105(1), 15-42. https://doi.org/10.1 002/jee.20112.

Sosa, E., Kim, J., Fantl, J., \& McGrath, M. (Eds.) (2008). Epistemology: An anthology, (2nd ed., ). Blackwell Publishing.

Staller, K. M. (2013). Epistemological boot camp: The politics of science and what every qualitative researcher needs to know to survive in the academy. Qualitative Social Work, 12(4), 395-413. https://doi.org/10.1177/14733250124 50483.

Star, S. L., \& Griesemer, J. R. (1989). Institutional ecology, 'translations' and boundary objects: Amateurs and professionals in Berkeley's Museum of Vertebrate Zoology, 1907-39. Social Studies of Science, 19(3), 387-420. https:// doi.org/10.1177/030631289019003001.

Steup, M. (1996). An introduction to contemporary epistemology. Prentice Hall. Tennis, J. (2008). Epistemology, theory, and methodology in knowledge organization: Toward a classification, metatheory, and research framework. Knowledge Organization, 35(2/3), 102-112. https://doi.org/10.5771/09437444-2008-2-3-102

Tracy, S. J. (2010). Qualitative quality: Eight "big-tent" criteria for excellent qualitative research. Qualitative Inquiry, 16(10), 837-851. https://doi.org/10.11 $77 / 1077800410383121$.

Tranquillo, J. (2013, June). The T-shaped engineer: Connecting the STEM to the TOP. ASEE Annual Conference \& Exposition, Atlanta, Georgia. doi:https://doi. org/10.18260/1-2\%2D\%2D22622

Willoughby, S. D., \& Johnson, K. (2017). Epistemic beliefs of non-stem majors regarding the nature of science: Where they are and what we can do. American Journal of Physics, 85(6), 461-468. https://doi.org/10.1119/1.4979654.

Yasar, O., \& Veronesi, P. (2015). Computational pedagogical content knowledge (CPACK): Integrating modeling and simulation technology into stem teacher education, 3514-3521 [Paper presentation]. Association for the Advancement of Computing in Education (AACE).
Yu, J. H., \& Strobel, J. (2011). Instrument development: Engineering-specific epistemological, epistemic and ontological beliefs. In Proceedings of the Research in Engineering Education Symposium, (pp. 1-8).

Yu, J. H., \& Strobel, J. (2012). A first step in the instrument development of engineering-related beliefs questionnaire. ASEE Annual Conference \& Exposition, San Antonio, Texas. https://doi.org/10.18260/1-2-20804.

\section{Publisher's Note}

Springer Nature remains neutral with regard to jurisdictional claims in published maps and institutional affiliations.

\section{Submit your manuscript to a SpringerOpen ${ }^{\circ}$ journal and benefit from:}

- Convenient online submission

- Rigorous peer review

- Open access: articles freely available online

High visibility within the field

- Retaining the copyright to your article

Submit your next manuscript at $\boldsymbol{\nabla}$ springeropen.com 